Abstracta Iranica Abstracta Iranica

Revue bibliographique pour le domaine irano-aryen

Volume 27 | 2006

Comptes rendus des publications de 2004

L'archéologie française en Perse et les antiquités nationales (1884-1914). Paris, Connaissances et Savoirs, 2004, 433 p., nombreux fac-similés, bibliog., index

Yann Richard

(2) OpenEdition

Journals

Édition électronique

URL : http://journals.openedition.org/abstractairanica/6060

DOI : 10.4000/abstractairanica.6060

ISSN : 1961-960X

Éditeur :

CNRS (UMR 7528 Mondes iraniens et indiens), Éditions de l'IFRI

Édition imprimée

Date de publication : 15 mai 2006

ISSN : 0240-8910

Référence électronique

Yann Richard, "L'archéologie française en Perse et les antiquités nationales (1884-1914). Paris,

Connaissances et Savoirs, 2004, 433 p., nombreux fac-similés, bibliog., index », Abstracta Iranica [En ligne], Volume 27 | 2006, document 219, mis en ligne le 02 janvier 2007, consulté le 25 septembre 2020. URL : http://journals.openedition.org/abstractairanica/6060 ; DOI : https://doi.org/10.4000/ abstractairanica.6060

Ce document a été généré automatiquement le 25 septembre 2020.

Tous droits réservés 


\title{
L'archéologie française en Perse et les antiquités nationales (1884-1914). Paris, Connaissances et Savoirs, 2004, 433 p., nombreux fac-similés, bibliog., index
}

\author{
Yann Richard
}

À part la recherche d'exotisme et l'expansion commerciale et industrielle, la découverte de l'Orient $\mathrm{du} 19^{\mathrm{e}} \mathrm{s}$. a consisté à retrouver dans les grands gisements archéologiques les sources de la civilisation de l'humanité. Les moyens modernes permettaient d'exhumer plus facilement des vestiges imposants et de les exporter vers les musées ou les galeries. L'Iran a constitué l'un des pôles d'intérêt pour cette passion d'archéologie, après la Grèce, l'Egypte, le Proche-Orient, la Mésopotamie et avant le Cambodge. On pourrait s'intéresser à cette passion du point de vue de la culture européenne et voir comment l'orientalisme et l'archéologie ont eu, tant sur le plan littéraire, esthétique que sur le plan des recherches philologiques et même religieuses, une importance grandissante et ont entraîné de plus en plus de savants vers l'étude de la Perse antique et médiévale. Nasiri-Moghaddam a choisi une voie complémentaire : l'étude de l'interaction de l'archéologie européenne avec la naissance du nationalisme en Iran. Après avoir décrit le contexte des relations politiques, économiques et culturelles entre les deux pays, il consacre un premier chapitre à la mission Dieulafoy (1884-1886) : les importantes découvertes de Suse, emportées en totalité vers la France malgré le partage prévu dans la convention eurent le mérite de faire découvrir au Louvre les merveilles de l'art achéménide (les fameux archers, la frise des lions...). La réaction iranienne entraîna l'arrêt des opérations pendant dix ans. Le ministre français à Téhéran, de Balloy, assisté du Dr. Tholozan, déployèrent des efforts innombrables pour trouver la voie permettant, à force de décorations, de cadeaux, de belles paroles et de voyages impériaux à Paris, d'envisager la poursuite des fouilles. En visitant les collections nationales à Paris en 1889, le souverain iranien comprenait l'importance de 
l'enjeu. La nouvelle convention fut négociée à partir de 1890. Aucune restriction morale n'arrêtait l'utilisation, par les Français, de pots-de-vin variés aux intermédiaires, notamment au Premier ministre Amīn os-Solțān. L'A. présente ensuite Jacques de Morgan (1857-1924), ingénieur de l'Ecole des Mines, qui dirigea une délégation scientifique importante, financée par des crédits exceptionnels. Les relations avec l'Iran ne changeaient pas après l'arrivée sur le trône de Mozaffaroddīn Šāh: la nouvelle convention a été falsifiée et les objets découverts ont été illégalement exportés. Lors du voyage qu'effectua le souverain à Paris en 1900 pour visiter l'Exposition universelle, on chercha à lui cacher les objets exposés au Louvre... mais le voyage s'étant fort bien déroulé - après la neutralisation d'un terroriste - le Shâh accorda à la France la concession tant attendue du monopole exclusif des recherches archéologiques avec droit d'emporter la totalité des objets découverts en Susiane. La mission de Suse devint alors une grande aventure pour les archéologues et épigraphistes. C'est l'époque où arrive à Paris le fameux Code d'Hammourabi (découvert en réalité avant le monopole, et illégalement exporté). Nasiri décrit les différentes campagnes de fouilles, y compris celles qui prospectent les autres régions que la Susiane (Tāleš, Marāqa, etc.). De Morgan, qui gérait de manière très personnelle des fonds qui rendaient jaloux tous ses collègues refusait de rendre des comptes, et s'attirait quelques animosités internes à la Délégation, fut l'objet d'une procédure administrative. Il dut passer la main à Roland de Mecquenem et fut innocenté, mais profondément affecté des attaques diverses dont les journaux se faisaient l'écho. Il ne démissionna définitivement qu'en 1912 après une dernière campagne de fouilles dans le nord-ouest de la Perse. Nasiri nous apprend que, démoralisé, ruiné, obligé de se retirer à Rome où la vie était moins chère, il fut notamment l'auteur du Chah du Mahboulistan (sous le pseudonyme de Karagueuz Effendi, 1923). Nasiri décrit la poursuite des fouilles après la dissolution de la Délégation, la mission d'Henry Viollet (1913). Les deux derniers chapitres concernent la réaction des autres puissances étrangères face au monopole revendiqué par la France (notamment la Grande-Bretagne, qui fit exploiter des fouilles clandestines) et enfin, le chapitre le plus original concerne l'attitude des élites iraniennes (notamment Nāṣer odDīn šāh) face au marché de l'art et de l'archéologie, et la naissance d'une administration nationale pour réglementer les fouilles et valoriser le patrimoine. Les annexes très riches apportent des documents français et persans, transcrits et en facsimilés. On peut regretter l'absence de photographies des sites et des objets. Mais le livre décrit de manière dense et intelligente les deux versants de l'histoire de l'archéologie française en Iran et restera comme un modèle d'analyse historique pour un phénomène lié aux contacts culturels et impériaux de l'Europe et de l'Orient; malgré l'importance des abus commis par les Français, il ne porte jamais de jugement et documente toutes ses descriptions à l'aide de documents d'archives originaux et la plupart inédits, tant français que persans. Rappelons qu'il est issu d'une thèse de la Sorbonne nouvelle (2002) distinguée par le prix annuel de la Foundation for Iranian Studies (États-Unis). 
INDEX

Thèmes : 4.3. Histoire de l'Iran moderne (à partir de 1905)

\section{AUTEURS}

YANN RICHARD

Sorbonne Nouvelle - Paris III 